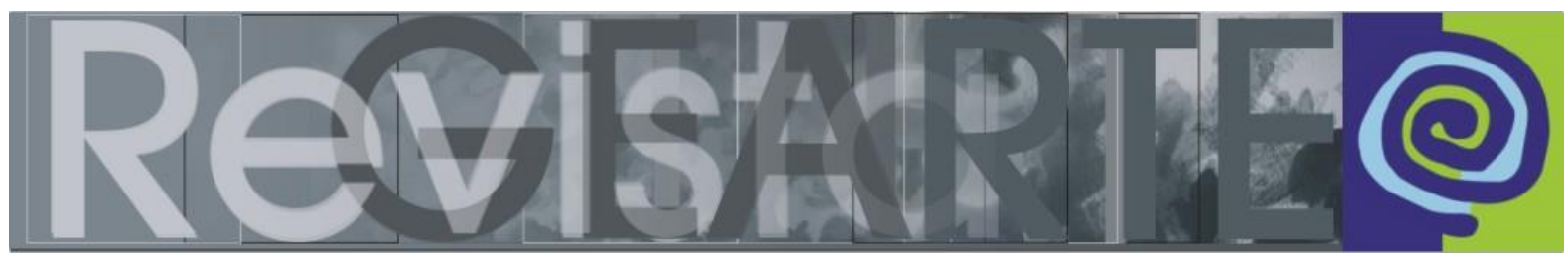

e-ISSN 2357-9854

\title{
GEARTE: uma das cartografias possíveis de sua história
}

\author{
Mirian Celeste Martins \\ (Universidade Presbiteriana Mackenzie — MACKENZIE, São Paulo/SP, Brasil)
}

RESUMO - GEARTE: uma das cartografias possíveis de sua história - Na tentativa de compor um possível panorama histórico do GEARTE, este texto apresenta uma cartografia que se iniciou com três informações: a listagem dos doutorados, dos mestrados e o sumário das revistas, todas sob a orientação de sua liderança efetiva e sensível - Analice Dutra Pillar e de todas e todos que com ela compartilham ideias e ideais. A cartografia revelou a riqueza de temas, conceitos e focos abrangentes que continuam a alimentar discussões e aprofundamentos que fomentam a formação contínua de educadores por meio da "partilha do sensível".

PALAVRAS-CHAVE

GEARTE. Arte. Ensino de arte. Coletivo criativo.

ABSTRACT - GEARTE: one of the possible cartographies of its history - In an attempt to compose a possible historical panorama of GEARTE, this text presents a cartography that began with three information: the list of doctorates, master's degrees and the summary of journals, all under the guidance of their effective and sensitive leadership - Analice Dutra Pillar and of everyone who shares ideas and ideals with her. Cartography has revealed the richness of broad themes, concepts, and focuses that continue to foment discussions and deepening that foster the continuing education of educators through "sharing the sensitive".

KEYWORDS

GEARTE; art; art teaching; creative collective.

[...] o modo estético do pensamento é bem mais que um pensamento da arte. É uma ideia do pensamento, ligada a uma ideia da partilha do sensível.

Jacques Rancière (2009, p. 68, grifo do autor).

Encontro na A partilha do sensível de Rancière (2009) uma chama para o início deste texto, que nasce muito antes, entre memórias saborosas de encontros com integrantes do GEARTE, entre palavras lidas em artigos e livros, entre imagens partilhadas em simpósios e congressos, entre trocas em bancas ou em mesas fartas de sabores e saberes.

Encontro em Rancière (2002; 2009) um modo estético do pensamento, um modo de olhar a lição de artistas, e é por aí que avanço na estreita relação entre professores-artistas e uma comunidade de pesquisa nascida em 1997 pelas mãos de Analice Dutra Pillar e hoje compartilhada entre muitos, tendo Maria Helena Rossi como 
vice-líder. Sonho nascido e fortalecido por nomes como o de Isabel Petry e seus memoráveis Seminários de Arte e Educação da Fundarte em Montenegro/RS. E tantos outros rostos que compõe esta comunidade de pesquisa e partilha!

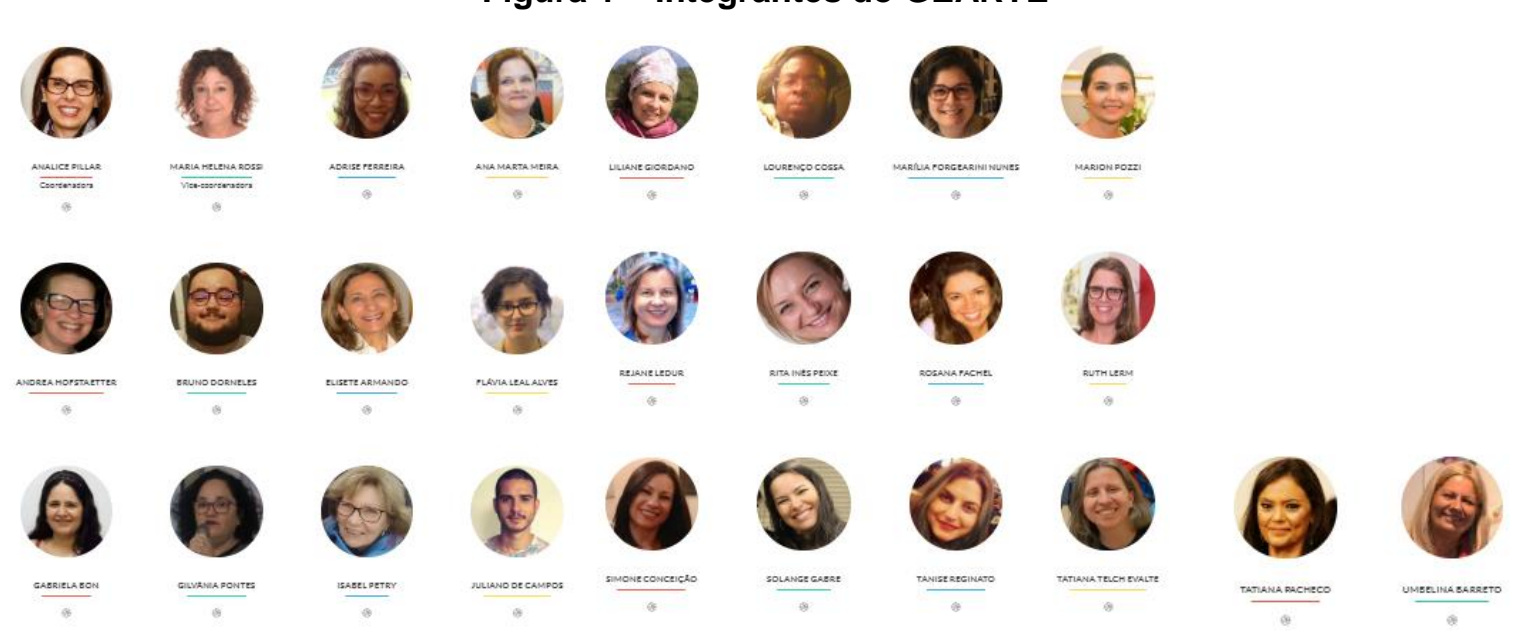

Fonte: <https://www.ufrgs.br/gearte/>. Acesso em 28 dez. 2018

Professores-artistas, com focos específicos de estudo e também com ideais e objetivos que se conectam e criam redes que cada vez mais se espalham e que criam novas redes. Um grupo que se une inicialmente como pós-graduandas(os) e sua orientadora e se fortalece tanto com aqueles que estiveram nessa condição e soltaram suas amarras, como com aqueles que hoje cursam a pós, além dos agregados, com maior ou menor proximidade. O logotipo do GEARTE traz em si a espiral que se alonga...

Por que professores artistas? Rancière propõe um modo estético do pensamento, ligada à ideia de partilha, em oposição à lição embrutecedora do professor que explica, aquele que não considera a inteligência e sensibilidade do outro e o coloca em oposição a si.

\begin{abstract}
A lição emancipadora do artista, oposta termo a termo à lição embrutecedora do professor, é a de que cada um de nós é artista, na medida em que adota dois procedimentos: não se contentar em ser homem de um ofício, mas pretender fazer de todo o trabalho um meio de expressão; não se contentar em sentir, mas buscar partilhá-lo. $\mathrm{O}$ artista tem necessidade de igualdade, tanto quanto o explicador tem necessidade de desigualdade. $\mathrm{E}$ ele esboça, assim, o modelo de uma sociedade razoável, onde mesmo aquilo que é
\end{abstract}


exterior à razão - a matéria, os signos da linguagem - é transpassado pela vontade razoável: a de relatar e de fazer experimentar aos outros aquilo pelo que se é semelhante a eles. (RANCIĖRE, 2002, p. 104).

No trabalho de todo o GEARTE vejo professoras e professores que são profissionais de um especial ofício e que também fazem de seu trabalho um meio de expressão e o partilham. Vejo o desejo de "relatar e de fazer experimentar aos outros aquilo pelo que se é semelhante a eles" e é exatamente por isso que ganha força e se expande cada vez mais. Por isso 21 anos! 22, 23,...

Como apresentar tantos anos de trabalho, de partilha, de aprofundamentos em um pequeno texto?

Cartografias fazem parte do meu modo de pensar. Quem me conhece mais de perto sabe que é esse o modo como as ideias nascem, como analiso dissertações e teses, como planejo ações e organizo o estudo e novos projetos. Mapas abertos, desmontáveis, reversíveis, como propõem Deleuze e Guattari (1995). E não poderia ser diferente ao escrever este texto sobre o GEARTE.

Uma cartografia não tem início nem final, pode ser lida com a multiplicidade que Ihe é própria como um rizoma, sem hierarquias ou chaves de leitura. E me deparei com uma riqueza de temas, conceitos, focos abrangentes e um desejo de entrar em cada convite formulado nas dissertações, nas teses, nos artigos, que tanto alimentam discussões e novos estudos. Assim, o desenho da cartografia iniciou com três informações: a listagem dos doutorados, dos mestrados e das revistas. O que é possível ler delas? Quais conexões são possíveis? E fui pinçando relações, sabendo que seria impossível dar conta da totalidade de tamanha produção! 
Figura 2 - Cartografia do GEARTE a partir de pesquisas em mestrados, doutorados e dos temas das revistas

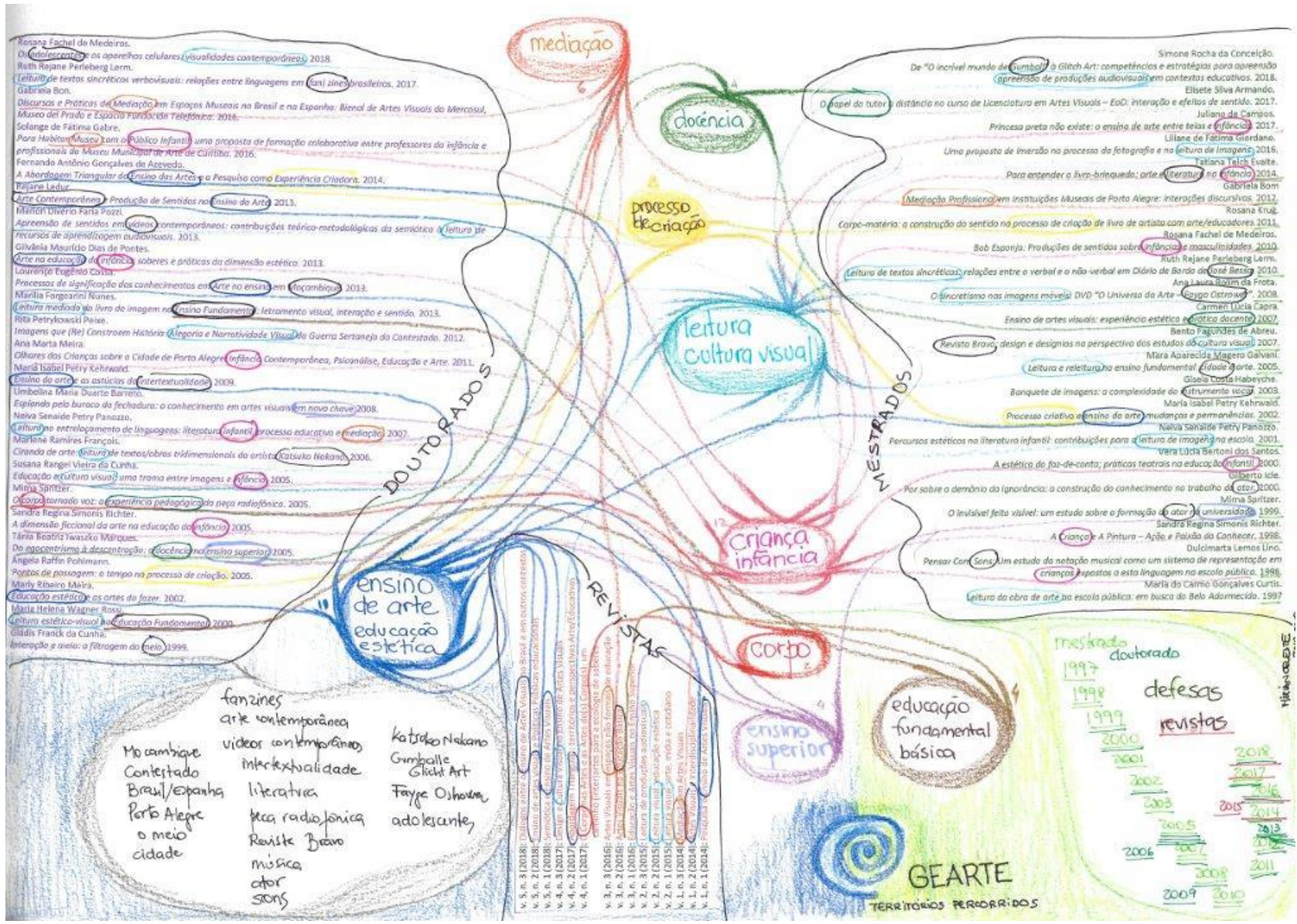

Fonte: A autora (2019).

Poderíamos dizer que o que está presente em toda a cartografia é a Arte e, evidentemente, a cultura. Sobre elas encontro agrupamentos possíveis.

Um dos destaques é o território da Leitura/cultura visual, com maior número de relações. Em 1997, a primeira dissertação defendida por Maria do Carmo Gonçalves Curtis, e em 2000 a primeira tese defendida por Maria Helena Rossi já anunciavam um caminho de muita contribuição ao ensino de arte no Brasil. O foco veio especialmente ampliando e fundamentando a abordagem triangular, proposta pela mestra de todos nós, Ana Mae Barbosa, que em 1991 lançava seu livro A imagem no ensino da Arte: anos oitenta e novos tempos, ainda trazendo no seu tripé a História da Arte e não a contextualização veiculada posteriormente (BARBOSA, 1998). Não se pode deixar também de citar uma obra fundamental de Analice Dutra Pillar (1999): 
A educação do olhar no ensino das artes. E, na mesma linha, antecedida por muitos artigos, a contribuição de Maria Helena Rossi (2003) com Imagens que falam.

Um território que se fortifica e se atualiza com as últimas teses que propõem o aprofundamento sobre as visualidade contemporâneas e os adolescentes, de Rosana Fachel de Medeiros (2018); sobre os (fan)zines brasileiros e as leitura de textos sincréticos verbo-visuais, de Ruth Rejane Perleberg Lerm (2017); e a últimas dissertações, que trazem a apreensão de produções audiovisuais, de Simone Rocha da Conceição (2018) e a leitura de imagens no processo da fotografia, por Liliane de Fátima Giordano (2016). Esse território também se presenta como tema nas edições da Revista GEARTE de 2015, 2017 e 2018.

Da leitura e cultura visual podemos percorrer um outro território que se conecta com Infâncias/ crianças, trazendo a tese de Susana Rangel Vieira da Cunha (2005): Educação e cultura visual: uma trama de imagens e infância, que se espalha em sua ação como doutora na mesma universidade, em suas publicações e cursos dados pelo Brasil. Destaca-se aqui também a dissertação de Sandra Regina Simonis Richter (1998): A criança e a pintura: ação e paixão do conhecer, que foi transformado em livro posteriormente e gerou um novo trajeto em tese defendida em 2005.

Esse extenso território se sobrepõe ao de Ensino de arte/educação estética, presente também nas edições da revista de 2014 e 2018 com maior aprofundamento. E se amplia para além das artes visuais, incluindo a música, com Dulcimara Lemos Lino (1998), o teatro com Vera Lucia Bertoni dos Santos (2000), a literatura com Neiva Senaide Petry Panozzo (2001 e 2007) e Tatiana Tech Evalte (2014).

A Educação Fundamental e Básica é um território também aqui amalgamado, presente nas edições da revista de 2016 e em vários trabalhos, assim como aqueles com foco no Ensino Superior, seja na formação do ator, como o de Mirna Spritzer (1999 e 2005) ou voltados à Docência, outro território que se volta à prática docente, como o de Carmen Lúcia Capra (2007). 
Destaca-se aqui a tese de Marly Meira (2002), que se une estreitamente com os territórios anteriores e de Fernando Antônio Gonçalves de Azevedo (2014): A abordagem triangular do ensino de artes e a pesquisa como experiência criadora. Ambas se vinculam também ao território de Processos de criação e com Maria Isabel Petry Kehrwald (2002 e 2009) e Rosana Krug (2011), além de outros.

Há ainda relações mais recentes com a medição em espaços museais, com Gabriela Bon (2012, 2016) e Solange de Fátima Gabre (2016), agrupados no território de Mediação, que também se estende a uma edição da revista, que foca os espaços não formais (2016). O corpo se faz presente, como foco na edição da revista (2017) e em outros tantos textos, pois a experiência sempre envolve pesquisandos e pesquisadores.

Há um universo de outros aspectos que brilham nos títulos de dissertações e teses. Vemos relações com o meio, tanto no Brasil como no exterior, especialmente Moçambique e Espanha. Vemos diferentes mídias e linguagens da arte: fanzines, peças radiofônicas, vídeos contemporâneos, sons, literatura, livros de artista... além de artistas e designers, entre outros, que se escondem dentro de tantos títulos.

A primeira dissertação foi defendida em 1997 e o primeiro doutorado em 1999, com a tese de Gládis Franck da Cunha. De lá para cá, a partir das informações do site do GEARTE, foram 22 mestrados e 24 doutorados, notando-se que nos anos de 2005 e de 2013 concentram-se muitas defesas. Muito trabalho para uma orientadora atenta e provocadora!

Haveria outras tantas cartografias se fossem agregados aqui os artigos e livros escritos por Analice Dutra Pillar, por Maria Helena Rossi, por todos e todas integrantes ou ex-integrantes deste grupo, seguindo o desejo de um rizoma nunca se fechar, mas impossível uma tarefa tão imensa como essa, pois são muitas as contribuições...

A cartografia ainda há de gerar outras configurações, dada a riqueza de tudo que a habita, ao mesmo tempo em que está em pleno movimento pelas dissertações, teses e edições da Revista GEARTE que estão em jogo neste momento. 
A rica cartografia também pode se sobrepor a uma outra, criada a partir do envio de três obras por Analice Dutra Pillar, por Maria Helena Wagner Rossi e por Maria Isabel Petry Kehrwald face da minha solicitação para que me enviassem uma imagem que fosse metáfora do GEARTE.

A obra de Beatriz Milhazes, Beleza Pura, 2006 foi enviada por Analice. A escolha atesta a diversidade manifesta nas mandalas, nas cores, nas texturas, nos brilhos e nas opacidades, nas linhas, nos pontos, nas formas fechadas... Há movimento que convida os olhos a andarilhar dentro e por entre as formas. Olhos incansáveis que não se cansam de perscrutar, de encontrar novos tons, outras formas que dialogam entre si. Na obra escolhida, sobressai uma espécie de flor que se abre em pétalas que nascem densas de cor e se desvanecem. Fico tentada em ver ali um início seguro, se abrindo e ocupando o espaço por traz do que vem à frente. Assim é o GEARTE, com sua rica multiplicidade de potências, continuando para além das fronteiras do tempo e do lugar...

Figuras 3 e 4 - Beatriz Milhazes, Beleza pura (detalhe) e M. C. Escher, Drawing Hands (detalhe) ${ }^{1}$
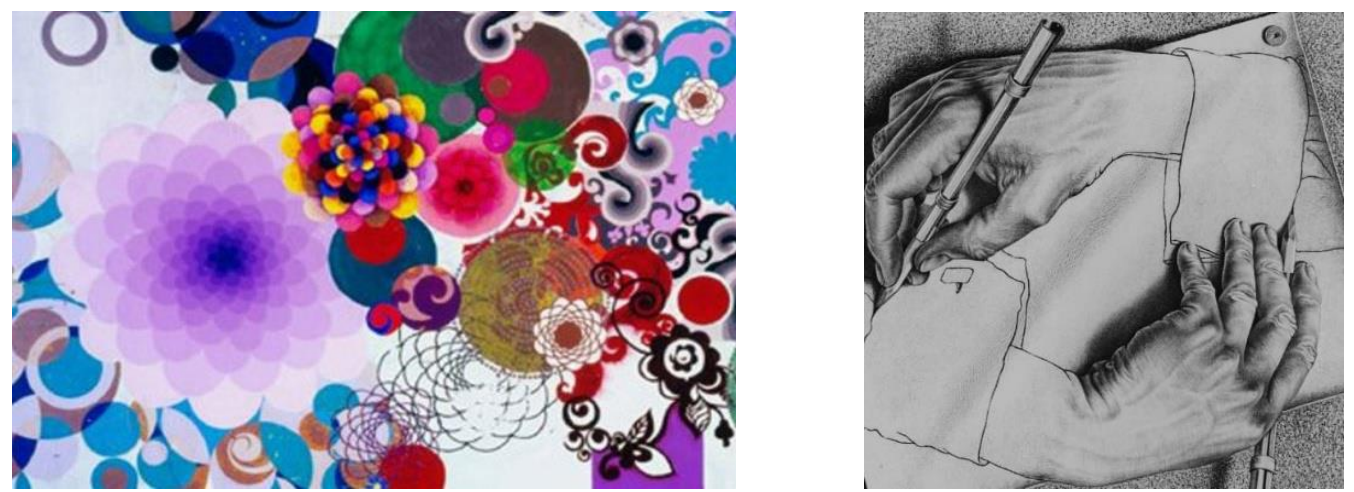

Fontes: http://enciclopedia.itaucultural.org.br/obra13694/beleza-pura https://www.mcescher.com/gallery/back-in-holland/drawing-hands

1 Figura 3: detalhe de Beleza Pura, 2006. Acrílica sobre tela, $199,50 \mathrm{~cm} \times 400,50 \mathrm{~cm}$. In: ENCICLOPÉDIA Itaú Cultural de Arte e Cultura Brasileiras. São Paulo: Itaú Cultural, 2019. Disponível em: <http://enciclopedia.itaucultural.org.br/obra13694/beleza-pura>. Acesso em: 08 jan. 2019. Verbete da Enciclopédia. Tendo como técnica acrílica sobre tela a obra tem $199.50 \mathrm{~cm} x$ $400.50 \mathrm{~cm}$. Figura4: detalhe de Drawing Hands, 1948. Litografia, 33,2cm x 28,2cm. Disponível em: <https://www.mcescher.com/gallery/back-in-holland/drawing-hands/>. Acesso em 08. jan. 2019. 
A litografia de Escher, denominada Drawing Hands, de 1948, poderia ser traduzida como Mãos desenhantes, e foi enviada por Maria Helena. Há nela um jogo visual entre o bi e o tridimensional, entre a linha e volume/sombras, entre o fundo e a folha de papel presa com tachinhas, entre o desenho fixado no papel e o gesto de quem o desenha; uma fita de Moebius que gira como uma mandala em movimento. Produção e produto, criação e registro, poderiam ser a metáfora deste grupo tão produtivo, nos quais cada gesto deixa marcas que constroem o percurso coletivo, ao mesmo tempo em que se alimentam dele para criar suas próprias trajetórias docentes, artísticas e sempre sensíveis.

Há uma outra imagem, enviada por Isabel Petry como metáfora do GEARTE.

Figura 3 - Guto Lacaz. Auditório para questões delicadas, 1989.Intervenção no lago do Parque do Ibirapuera na cidade de São Paulo

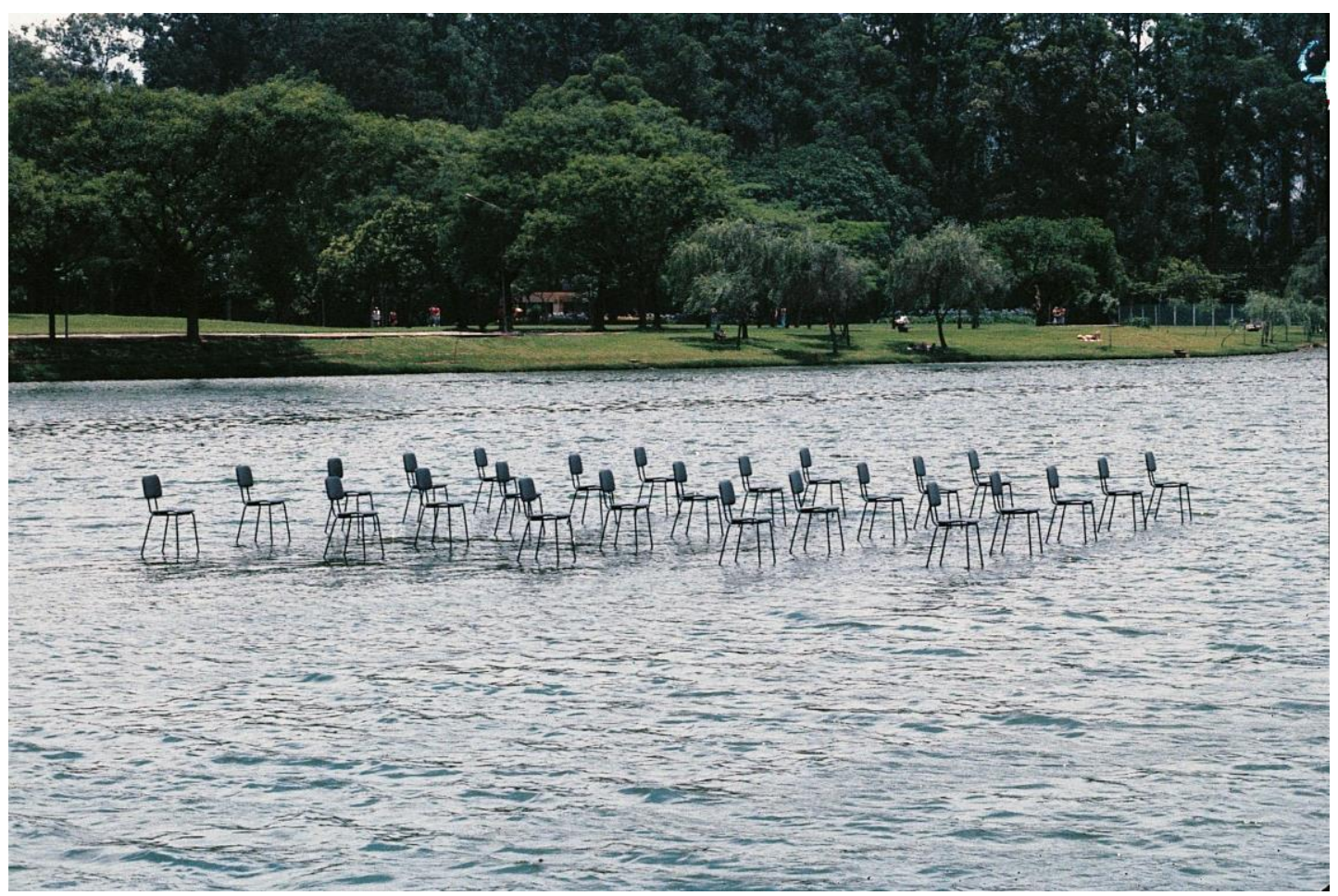

Foto Rômulo Fialdini. Fonte: http://www.vitruvius.com.br/revistas/read/resenhasonline/17.195/6893

Isabel justificou sua escolha no e-mail enviado: "a delicadeza, a leveza, a busca constante do GEARTE pelo saber e, ao mesmo tempo, a ação instigante, a força proativa de um coletivo criativo, liderado por pessoas delicadas e sensíveis tal qual esse Auditório." E se vê "instalada" em uma das cadeiras, com os pés na água, 
aguardando a reunião das terças-feiras. E afetivamente se refere a mim, que lhe mostrei essa imagem em uma palestra.

Além do que se vê na imagem, a obra nos faz lembrar do que é colocar em pé um projeto, o que é colocar em movimento um coletivo, pois a potência sofre também a concorrência de tantos afazeres docentes, dos estudos e focos de cada integrante. Guto Lacaz também viveu uma experiência trabalhosa para manter a obra ao ar livre, onde a natureza se impõe com os ventos, o calor e a chuva, a dinâmica da água. Fez muitas experiências até encontrar um jeito de manter as cadeiras flutuando e nos transportar imaginativamente para esse auditório para questões realmente delicadas.

Seja a natureza para Lacaz, seja a riqueza imensa de cada integrante, podemos afirmar com Deleuze (1992, p. 156):

O essencial são os intercessores. A criação são os intercessores. Sem eles não há obra. Podem ser pessoas - para um filósofo, artistas ou cientistas; para um cientista, filósofos ou artistas - mas também coisas, plantas, até animais, como em Castañeda. Fictícios ou reais, animados ou inanimados, é preciso fabricar seus próprios intercessores. É uma série. Se não formamos uma série, mesmo que completamente imaginária, estamos perdidos. Eu preciso de intercessores para me exprimir, e eles jamais se exprimiriam sem mim: sempre se trabalha em vários, mesmo quando isso não se vê. $E$ mais ainda quando é visível: Félix Guattari e eu somos intercessores um do outro.

São os intercessores que nos levam aonde ainda não imaginamos ir e que em um grupo de pesquisa, de estudo e de amorosidades, nos fazem ampliar o desejo de partilha e de manter um pensamento estético. E isso implica em muito trabalho! Para Rancière (2009, p. 68): "É preciso sair do esquema preguiçoso e absurdo que opõe o culto estético da arte pela arte à potência ascendente do trabalho operário. [...] O culto da arte supõe uma revalorização das capacidades ligadas à própria ideia de trabalho".

Como operárias e operários da arte e da educação, temos diante de nós uma infinidade de tarefas e um desejo imenso de trazer para a escola e para a universidade, para os museus e para as cidades e o campo, um modo de ver, pensar e ativar a arte. E o GEARTE nos alimenta e nos dá energia para continuar...

\section{Vida longa ao GEARTE!}




\section{Referências}

AZEVEDO, Fernando Antônio Gonçalves de. A abordagem triangular do ensino das artes e a pesquisa como experiência criadora. 2014. Tese (Doutorado em Educação) - Faculdade de Educação, Universidade Federal do Rio Grande do Sul, Porto Alegre.

BARBOSA, Ana Mae. Tópicos utópicos. Belo Horizonte: C/Arte, 1998.

BARBOSA, Ana Mae. A imagem no ensino da arte: anos oitenta e novos tempos. São Paulo: Perspectiva; Porto Alegre: Fundação IOCHPE, 1991.

BON, Gabriela. Discursos de práticas de mediação em espaços museiais no Brasil e na Espanha: Bienal de Artes Visuais do Mercosul, Museo del Prado e Espacio Fundación Telefonica. 2016. Tese (Doutorado em Educação) - Faculdade de Educação, Universidade Federal do Rio Grande do Sul, Porto Alegre.

BON, Gabriela. Mediação Profissional em instituições museais de Porto Alegre: interações discursivas. 2012. Dissertação (Mestrado em Educação) - Faculdade de Educação, Universidade Federal do Rio Grande do Sul, Porto Alegre.

CAPRA, Carmen Lúcia. Ensino de artes visuais: experiência estética e prática docente. 2007. Dissertação (Mestrado em Educação) - Faculdade de Educação, Universidade Federal do Rio Grande do Sul, Porto Alegre.

CONCEIÇÃO, Simone Rocha da. De "O incrivel mundo de Gumball" à Glitch Art: competências e estratégias para apreensão de produções audiovisuais em contextos educativos. 2018. Dissertação (Mestrado em Educação) - Faculdade de Educação, Universidade Federal do Rio Grande do Sul, Porto Alegre.

CUNHA, Susana Rangel Vieira da. Educação e cultura visual: uma trama de imagens e infância. 2005. Tese (Doutorado) - Faculdade de Educação, Universidade Federal do Rio Grande do Sul, Porto Alegre.

CURTIS, Maria do Carmo Gonçalves. Leitura da obra de arte na escola pública: em busca do belo Adormecido. 1997. Dissertação (Mestrado em Educação) - Faculdade de Educação, Universidade Federal do Rio Grande do Sul, Porto Alegre.

DELEUZE, Gilles. A transformação do padeiro. In: Conversações, 1972-1990. Rio de Janeiro: Editora 34, 1992.

DELEUZE, Gilles; GUATTARI, Félix. Rizomas. In: Mil platôs. Rio de Janeiro: Editora 34, 1995 (Volume 1).

EVALTE, Tatiana Tech. Para entender o livro-brinquedo: arte e literatura na infância. 2014. Dissertação (Mestrado em Educação) - Faculdade de Educação, Universidade Federal do Rio Grande do Sul, Porto Alegre.

GABRE, Solange de Fátima. Para habitar museu com o público infantil: uma proposta de formação colaborativa entre professores da infância e profissionais do Museu Municipal de Arte de Curitiba. 2016. Tese (Doutorado em Educação) - Faculdade de Educação, Universidade Federal do Rio Grande do Sul, Porto Alegre.

GEARTE. Revistas. Disponível em: <https://seer.ufrgs.br/gearte/index>. Acesso em 20 dez 2018.

GIORDANO, Liliane de Fátima. Uma proposta de imersão no processo da fotografia e na leitura de imagens. 2016. Dissertação (Mestrado em Educação) - Faculdade de Educação, Universidade Federal do Rio Grande do Sul, Porto Alegre.

KEHRWALD, Maria Isabel Petry. Ensino da arte e as astúcias da intertextualidade. 2009. Tese (Doutorado em Educação) - Faculdade de Educação, Universidade Federal do Rio Grande do Sul, Porto Alegre. 
KEHRWALD, Maria Isabel Petry. Processo criativo e ensino da arte: mudanças e permanências. 2002. Dissertação (Mestrado em Educação) - Faculdade de Educação, Universidade Federal do Rio Grande do Sul, Porto Alegre.

KRUG, Rosana. Corpo-matéria: a construção do sentido no processo de criação de livro de artista com arte/educadores. 2011. Dissertação (Mestrado em Educação) - Faculdade de Educação, Universidade Federal do Rio Grande do Sul, Porto Alegre.

LERM, Ruth Rejane Perleberg. Leitura de textos sincréticos verbovisuais: relações entre linguagens em (fan) zines brasileiros. 2017. Tese (Doutorado em Educação) - Faculdade de Educação, Universidade Federal do Rio Grande do Sul, Porto Alegre.

LINO, Dulcimara Lemos. Pensar com sons: um estudo da notação musical como um sistema de representação em crianças expostas a esta linguagem na escola pública. 1998. Dissertação (Mestrado em Educação) - Faculdade de Educação, Universidade Federal do Rio Grande do Sul, Porto Alegre.

MEDEIROS, Rosana Fachel de. Os adolescentes e os aparelhos celulares: visualidades contemporâneas. 2018. Tese (Doutorado em Educação) - Faculdade de Educação, Universidade Federal do Rio Grande do Sul, Porto Alegre.

MEIRA, Marly Ribeiro. Educação estética e as artes do fazer. 2002. Tese (Doutorado em Educação) Faculdade de Educação, Universidade Federal do Rio Grande do Sul, Porto Alegre.

PANOZZO, Neiva Senaide Petry. Leitura no entrelaçamento de linguagens: literatura infantil, processo educativo e mediação. 2007. Tese (Doutorado em Educação) - Faculdade de Educação, Universidade Federal do Rio Grande do Sul, Porto Alegre.

PANOZZO, Neiva Senaide Petry. Percursos estéticos na literatura infantil: contribuições para a leitura de imagens na escola. 2001. Dissertação (Mestrado em Educação) - Faculdade de Educação, Universidade Federal do Rio Grande do Sul, Porto Alegre.

PILLAR, Analice Dutra (Org.). A educação do olhar no ensino das artes. Porto Alegre: Mediação, 1999.

RANCIÈRE, Jacques. O mestre ignorante: cinco lições sobre a emancipação intelectual. Belo Horizonte: Autêntica, 2002.

RANCIÈRE, Jacques. A partilha do sensível: estética e política. São Paulo: Editora 34, 2009.

RICHTER, Sandra Regina Simonis. A dimensão ficcional da arte na educação da infância. 2005. Tese (Doutorado em Educação) - Faculdade de Educação, Universidade Federal do Rio Grande do Sul, Porto Alegre.

RICHTER, Sandra Regina Simonis. A Criança e a Pintura: ação e paixão do conhecer. 1998. Dissertação (Mestrado em Educação) - Faculdade de Educação, Universidade Federal do Rio Grande do Sul, Porto Alegre.

ROSSI, Maria Helena Wagner. Imagens que falam. Porto Alegre: Mediação, 2003.

ROSSI, Maria Helena Wagner. Leitura estético-visual na Educação Fundamental. 2000. Tese (Doutorado em Educação) - Faculdade de Educação, Universidade Federal do Rio Grande do Sul, Porto Alegre.

SANTOS, Vera Lucia Bertoni dos Santos. A estética do faz-de-conta: práticas teatrais na educação infantil. 2000. Dissertação (Mestrado em Educação) - Faculdade de Educação, Universidade Federal do Rio Grande do Sul, Porto Alegre.

SPRITZER, Mirna. O corpo tornado voz: a experiência pedagógica da peça radiofônica. 2005. Tese (Doutorado em Educação) - Faculdade de Educação, Universidade Federal do Rio Grande do Sul, Porto Alegre.

SPRITZER, Mirna. O invisível feito visível: um estudo sobre a formação do ator na universidade. 1999. Dissertação (Mestrado em Educação) - Faculdade de Educação, Universidade Federal do Rio Grande do Sul, Porto Alegre. 
Mirian Celeste Martins

Professora do Programa de Pós-graduação em Educação, Arte e História da Cultura e do Curso de Pedagogia da Universidade Presbiteriana Mackenzie onde coordena os Grupos de pesquisa: Arte na Pedagogia e Mediação Cultural: provocações e mediações estéticas. Professora aposentada do Instituto de Artes/UNESP. Atuou também na Faculdade Santa Marcelina e no Espaço Pedagógico. Foi presidente da Associação de arte-educadores do Estado de São Paulo (1985-1989) e secretária da FAEB - Federação de arte-educadores do Brasil. Dentre suas publicações destaca-se a coautoria de Teoria e Prática do Ensino de Arte (FTD2011) que faz parte do PNBE-Professor do Ministério da Educação. Coautora de Por trás da cena, projeto aprovado e financiado pelo Petrobrás Cultural (2010). Tem mestrado em Artes pela Universidade de São Paulo (1992) e doutorado em Educação pela Universidade de São Paulo (1999).

E-mail:mcmart@uol.com.br

Currículo: http://lattes.cnpq.br/7167254305943668

Recebido em 15 de janeiro de 2019 Aceito em 20 de fevereiro de 2019 